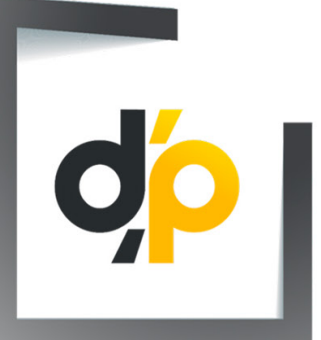

d.perspectivos siglo XXI

VOLUMEN 7 NÚMERO 13

3 DE MARZO DEL 2020
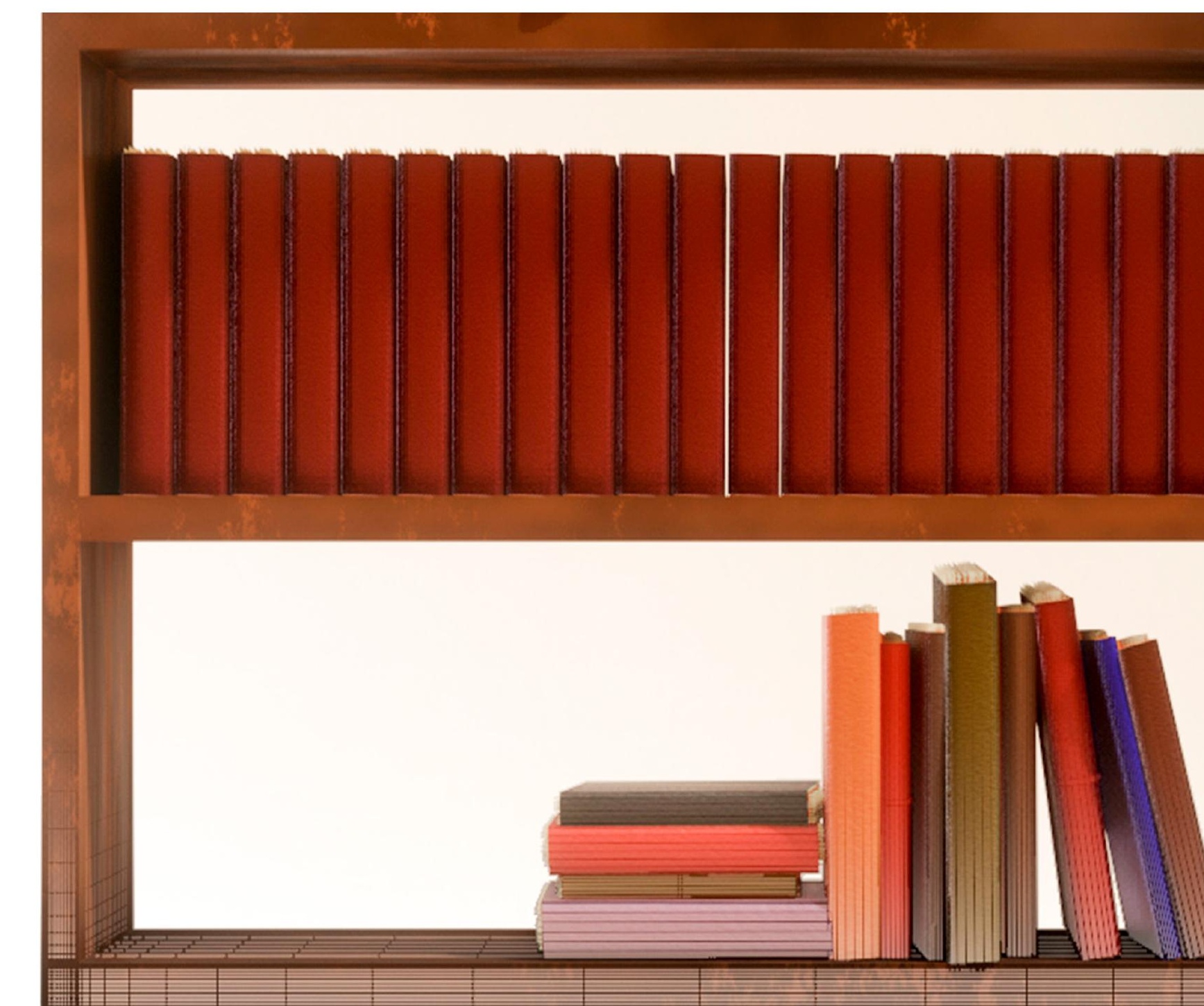

章

4

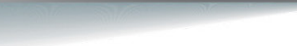




\section{Vicisitudes de la formación y práctica docente a través del tiempo}

\section{Vicissitudes of teacher training and practice over time}

\section{d}

María Guadalupe Alonso Segura

Maestría en Investigación de la Educación Sec. Of. No. 0423 “Dr. José María Luis Mora”, Texcoco

Contacto: gpe_alonsompr73@hotmail.com

Recepción: 18/09/2019

Aceptación: 06/11/2019

DOI: http://doi.org/10.53436/k2a18VO3

\section{Resumen}

Para hablar de la formación y la práctica docente es sustancial partir del pasado, así se comprenderán sus cambios, permanencias, historicidad y vicisitudes; del mismo modo se entenderá el rol del docente como elemento de reproducción y transformación de la política educativa implícita en los planes y programas de estudio. En este escrito se presentan grosso modo las principales características de dicha práctica desde una perspectiva histórica, en la que se destacan los ideales educativos de los grupos de poder y la necesidad de construir un proyecto educativo capaz de incidir en la atención de los niños ante el problema del analfabetismo en el país. Se verá la influencia del contexto histórico-social en la formación y ejercicio magisterial para responder a las expectativas planteadas desde los siglos XIX y XX, la configuración del maestro en la actualidad, la puesta en marcha de los ideales inherentes en la Constitución y las leyes en que se desenvolvió y se desenvuelve, además de la manera en cómo responde ante las necesidades políticas, económicas y sociales. El propósito es poner de manifiesto el tránsito del desempeño de estos profesionales desde el pasado hasta la actualidad, con fundamento en su formación, así como en las vicisitudes para perpetuar o transformar dicha labor.

Palabras clave: Práctica docente, Formación, Ideal educativo, Transformación.

\section{Abstract}

To speak about teacher training and practice, it is essential begin with the past, in this way, its changes, its permanencies, its historicity and its vicissitudes will be understanded, likewise, the role of the teacher will be understanded as an element of reproduction and transformation of the educational policy implied in the plans and study programs, curriculum, etc. In this writing, the main characteristics of this practice are roughly presented, from a historical 
perspective where the educational ideals of powerful groups and the need to build an educational project capable of influencing the children attention to confront the problem of illiteracy in the country are highlighted. It will be shown the influence of historical-social context in the magistral training and development to respond the expectations suggested since the XIX and XX centuries, the configuration of the teacher currently, the implementation of these ideals inherent in the Constitution and the laws in which the teacher has been developed and is developing, also the way in which they responded in the presence of political, economic, and social needs. The purpose is to evince the achievement of this professionals from past to present, based on their training as well as the vicissitudes to perpetuate or transform their work.

Key words: Teaching practice, Teachertraining, Educationalideal, Transformation.

\section{Introducción}

La temática de este escrito se deriva de un trabajo de investigación en curso intitulado "Centralización y federalización de la enseñanza en México durante el siglo XIX y XX", el cual está inscrito en una perspectiva teórica históricoeducativa, donde se destaca la conformación de la educación y práctica del docente a través del tiempo.

En primera instancia, pareciera fácil hablar de este actor educativo, de su ejercicio cotidiano, de su enseñanza, de la construcción de su propia ideología, de su actuar como portador de un currículo, de los problemas cotidianos que enfrenta, los cuales además no sólo se quedan en un edificio escolar: sus acciones y valores trascienden en la comunidad, porque su figura se hizo necesaria para generar un vínculo con alumnos, padres de familia y autoridades. No obstante, el índice de analfabetismo fue muy elevado aún en las primeras décadas del siglo XX y los maestros eran pocos y con situaciones adversas para atender un problema nacional. Por ello se pregunta: ¿Cómo se constituyó la formación y la práctica docente durante los siglos XIX y XX ante las adversidades y cómo trasciende en el presente?

Para responder lo anterior se parte de la tesis principal de que la práctica y la formación docente se han erigido en el tiempo en las instituciones educativas (de una manera formal), sin embargo, existen obstáculos y realidades socioculturales que influyen en la puesta en marcha de los proyectos educativos federales y marcan los propósitos educativos a lograr, donde el maestro tiene la capacidad de adaptarlos, adoptarlos y enarbolarlos 
como propios para continuar su reproducción o reflexionar su práctica para su transformación.

El desarrollo del trabajo se divide como sigue: primero, de forma sucinta se describe el contexto nacional del proyecto educativo en el siglo XIX; enseguida, se refiere la práctica y formación docente en el siglo XIX; después, se reseña su transición al siglo XX y cómo se desenvolvió en este mismo; posteriormente, se hace referencia a la formación y la práctica docente del maestro hacia finales de ese y a algunos de sus rasgos durante el siglo XXI, y se finaliza con las conclusiones.

\section{Conociendo el contexto}

En la historia de México se ha observado la influencia de las políticas educativas a través de los proyectos a los que da lugar, estos han contenido ciertos intereses e intenciones basados en idearios elaborados por una élite y representados por los gobernantes en turno. Estos idearios fueron y han sido plasmados en la Constitución, en reglamentos para ofrecerles legitimidad y han cubierto la satisfacción de intereses económicos, políticos, legales y sociales requeridos en el momento histórico. Al hablar de aspectos políticos se hace referencia a establecer "relaciones de poder, en las cuales, las condiciones, los criterios y las orientaciones están determinadas por necesidades oficiales" (Carrizales, 1986, p. 41). Esos proyectos se encuentran en las teorías educativas, el currículum, los planes y programas de estudio y requieren que se les dé vida al ponerlos en práctica por los diferentes actores educativos (maestros, autoridades, padres de familia, alumnos).

De esta manera, se configura el modelo de enseñar y aprender, los rasgos de la figura del maestro y de los alumnos, su deber ser, es decir, la aspiración del ideal al que se pretende llegar, lo cual marca la alienación de la actuación de los actores educativos. Esto también sucede actualmente, pero ¿cómo sucedió en el pasado?

\section{Práctica educativa y formación en el siglo XIX}

Al finalizar la Independencia en 1821, surgió la necesidad de tener un proyecto de nación y por consiguiente uno educativo que contuviera los ideales del grupo político en el poder, así, las facciones liberales y conservadoras trataron de 
establecer una nueva aspiración "lograr una instrucción de las primeras letras para lograr la libertad" (Staples, 2012, p. 100) y buscar el progreso material. Bajo este ideal o aspiración política durante el siglo XIX, parecían coincidir las fuerzas federales (liberales) y centralistas (conservadores), de esta forma cualquier facción pretendía alcanzar la ansiada utopía de la manipulación, elaborada por la élite cuyo "objetivo [fue] sustituir el conocimiento de la realidad con una versión deformada de la misma (...) para formar buenos y responsables ciudadanos o que en el profesor radicara la calidad de la educación" (Carrizales, 1986, p. 18).

El maestro, al estar influenciado por estas políticas, idearios y reglamentos realiza su práctica docente concebida como el "proceso de aprendizaje a través del cual se reconstruye su formación adaptándola a la profesión, eliminando lo que les parece inutilmente abstracto o sin relación con la realidad vivida y conservando lo que pueda servirles" (Tardif, 2014, p. 41). Ante este concepto, el maestro de la segunda mitad del siglo XIX asumió esa práctica con base en las condiciones de su contexto, con necesidades propias similares a las de comunidades en pobreza que atendía. Además, en el siglo XIX surgieron las Escuelas lancasterianas -desde 1822 hasta 1890-, organizadas y financiadas por una sociedad de beneficencia, integrada por políticos, escritores y clérigos, cuyo fin fue formar buenos ciudadanos y obreros calificados.

Durante esta época existió una escasa inversión del erario en el ámbito educativo, porque la mayoría del presupuesto se invertía en las guerras padecidas en el país, así en 1861 esta situación de pobreza se veía reflejada en las escuelas donde "los maestros eran pocos y muchos de ellos tenían una formación deficiente. Aparte (...) las familias [no enviaban] a sus hijos regularmente a la escuela, no era lo común, no se formaba el hábito de la asistencia" (Bermúdez, 2002, pp. 117-118), principalmente por las costumbres, las creencias y las condiciones de escasa salud en ese periodo. Los maestros se preparaban en las Normales lancasterianas, en ellas su formación tenía una duración de seis meses y ningún curso de pedagogía.

El maestro con sus incipientes conocimientos asistió a la escuela para transmitir sus conocimientos; no obstante, al desarrollar su práctica de forma cotidiana acumuló otros más. Por ello, el saber docente en cada época histórica sigue siendo "esencialmente heterógeneo: el saber plural, formado por diversos saberes provenientes de las instituciones de formación profesional, de los currículos y de la práctica cotidiana" (Tardif, 2014, p. 41). 
Los maestros al realizar su práctica utilizaron los recursos de los que disponían, en algunas ocasiones contaron con mobiliario para desempeñar su actividad y entre los materiales utilizados por los alumnos están "las plumas de ave, la tinta y el papel para los avanzados, o la tiza y los pizarrines para los principiantes" (Bermúdez, 2002, p. 118). No contaban con libros ni útiles, posiblemente esto pudo ser un obstáculo para la enseñanza, además, los edificios escolares eran improvisados. A los alumnos se les consideró como "actores pasivos, se les obligaba o se les prohibía asistir a la escuela, según el criterio [del padre]" (Staples, 2012, p. 105).

La figura del maestro en la escuela lancasteriana fue la de "una persona que sabe algo y cuya función consiste en transmitir ese saber a otros" (Tardif, 2014, p. 25); así, lo poco que sabía lo podía dar a conocer a los alumnos, no sólo conocimientos sino otras habilidades como dibujar o desarrollar un oficio; también se le infundía la necesidad de imponer la disciplina, utilizando un método cuyo lema fue "la letra con sangre entra". El maestro estableció el miedo en la escuela a través de la utilización "de un látigo, palmeta o varilla de uso frecuente, lo que hacía de ella un lugar de fastidio, de humillación, de lágrimas y de dolor para los niños, que no tenían buena memoria" (Staples, 2012, p. 106); entonces lo importante era aprender conocimientos, sin comprenderlos, pero sí memorizarlos. Se observaba un pradigma tradicional de orden que la época pudo requerir porque de forma simultánea se introdujo el positivismo (teoría basada en el orden, progreso y libertad) y prácticas de los maestros, las cuales fueron aceptadas sin ningún cuestionamiento.

El emperador Maximiliano de Habsburgo (1864-1867) asumió una ideología liberal, aunque fue representante del bando conservador; sin embargo, durante su permanencia en el poder pretendió ensalzar la imagen del maestro y abrir escuelas "donde niños y adultos aprendieran las primeras letras en su lengua materna y en español" (Bermúdez, 2002, p. 120). Asimismo, el proyecto educativo del emperador fue dirigido a "la población india, programa que intentó incluirlos y hacerlos partícipes de la vida nacional [porque contempló] al indio como el buen salvaje" (Bermúdez, 2002, p. 121). Como consecuencia, los maestros no sólo atendían a niños en edad escolar sino a adultos analfabetas, en horarios nocturnos y, en algunas ocasiones, los domingos, porque era su día de descanso y los podían encontrar en la comunidad. La revalorización de los indios, de los maestros y las mujeres sólo duró hasta 1867.

Las maestras de mediados del siglo XIX tenían que cumplir ciertos requisitos 
para ser respetadas y aceptadas, más en el orden social que formativo, debían ser:

Virtuosas señoras, señoritas a quienes la veleidosa fortuna les había vuelto la espalda, y se habían visto obligadas a desempeñar alguna labor remunerada que las protegiera del fango. La labor magisterial no entraba en conflicto con su misión primordial que consistía en ser dóciles esposas y madres ejemplares. (Bermúdez, 2002, p. 122).

Como se expone en el párrafo anterior, el trabajo de los maestros lo desempeñaron personas con ciertas características y de acuerdo a su género, su rol social, su "formación, el pensamiento de los docentes y a su historia de vida, a las relaciones entre la cultura escolar y la cultura de profesorado" (Tardif, 2014, p. 167). Con ello conformaron sus saberes sociales, los cuales les permitían combinarlos con la cultura escolar y la cultura del profesorado. Durante los gobiernos de Benito Juárez y Sebastián Lerdo de Tejada, quienes representaron el periodo de la República Restaurada, intentaron establecer en la educación "un plan de estudios uniforme que diera configuración y encauzara a una nación independiente (...) además de uniformar la mentalidad de los ciudadanos" (Bermúdez, 2002, p. 124). También impulsaron la idea de que los textos utilizados en las escuelas "debían ser escritos por mexicanos".

\section{La transición de la práctica educativa de finales del siglo XIX al $\mathbf{X X}$}

Al iniciar el periodo histórico del porfiriato (1876-1910), comenzó una nueva etapa de estabilidad, la cual permitió tener algunos avances educativos, principalmente por el orden establecido por el gobierno de Díaz y la preocupación de los secretarios de instrucción pública como Joaquín Miranda y Justo Sierra, pues veían en la educación un elemento para lograr el progreso de México; para ello, se pensaba en el ideal del ciudadano y por consiguiente cimentaron los primeros pasos para la uniformidad de la enseñanza a través de los planes y programas, independientemente de las diferencias territoriales, culturales y económicas del país. Durante este periodo la linealidad de la enseñanza significó la uniformidad del pensamiento encerrándolo en la frase siguiente "cuando los hombres leen y piensan lo mismo, están inclinados a obrar del mismo modo" (Bazant, 2002, p. 131), la preocupación era por aquellos que no se sabía lo que leían o estaban aprendiendo.

Al comienzo del gobierno de Díaz, las estadísticas educativas demostraban lo siguiente: 
[El] 50\% de la población total no sabía leer ni escribir... Maestros había muy pocos; no alcanzaban a cubrir las necesidades del país. Se llegaba al extremo de carencia de alumnos, ya que los pequeños eran fuerza de trabajo que cooperaba con la sobrevivencia de su familia. (Bermúdez, 2002, p. 127)

Por consecuencia, los establecimientos escolares tendían a cerrarse.

El fin de la educación fue "inculcar a los niños el amor a la patria, al orden, a la libertad, al progreso, a las ciencias. Se deseaba crear generaciones de mexicanos trabajadores y progresistas, amantes de su patria, del orden y de la filantropía" (Bazant, 2002, p. 132). Por lo menos, esa fue la aspiración del gobierno federal, lo cual era la característica de la teoría positivista en México.

\section{Práctica docente y formación en el siglo XX}

La práctica docente en este siglo fue concebida como "la unidad de pensar y el hacer, es la síntesis entre experiencia y comportamiento" (Carrizales, 1986, p. 45). Era un ejercicio intelectual que le permitía al maestro reflexionar su quehacer cotidiano, construir metas propias o direccionadas desde las autoridades educativas, con la aspiración a la transformación de sus saberes experienciales y formativos. Esta conceptualización, permitió analizar una serie de modificaciones educativas que se desarrollaron durante el periodo del porfiriato, pero fueron consolidadas durante las primeras décadas del siglo $\mathrm{XX}$, de esta manera se le exigía al maestro tener una actitud de compromiso social, no sólo en el aula sino en su contexto, desarrollando saberes sociales, los cuales le permitieron adaptarse y mimetizarse en la comunidad donde laboraba.

La práctica docente en la educación primaria comenzaba con la atención a los alumnos, los cuales no siempre tenían la misma edad, porque en ese momento asistían a las escuelas adultos y niños para iniciar su proceso de alfabetización, por lo que enseñar requirió mayor esfuerzo.

Con las nuevas teorías educativas y pedagogos como Enrique Rébsamen y Laubcher, se ofrecieron ciertas directrices de cómo tendría que ser la enseñanza; de esta manera, el maestro tuvo que adoptar el método objetivo, el cual consistía en: 
Educar al niño por medio de la observación de los objetos materiales. Este modelo suplantaba al dogmático de épocas anteriores donde el niño estaba obligado a aprender de memoria los conocimientos expuestos por el maestro. Ahora, inclusive, se afirmaba que el exceso de memoria era dañino para la salud. (Bazant, 2002, p. 132)

Aunque esto se mencionaba en el discurso, continuaron las prácticas de castigos y de aprendizaje memorístico, debido a que cada seis meses las autoridades gubernamentales o personas de prestigio social examinaban a los alumnos para evaluar los ramos de lectura, gramática, aritmética, urbanidad, moral, escritura y, en el caso de las niñas, se evaluaba la costura. ${ }^{1}$

En este periodo se utilizó un modelo paternalista para educar a los niños, el maestro era misionero, "La escuela únicamente exigía que fueran los niños limpios, peinados y que tuvieran zapatos. Ahí mismo se les distribuía papel, lápices, libros; ocasionalmente ropa y zapatos" (Bazant, 2002, p. 134). Además, les enseñaban un oficio con la finalidad de tener mayor asistencia en los establecimientos escolares y apoyar en la disminución del analfabetismo, así como la de brindar apoyo a la comunidad donde se laboraba.

Las escuelas lancasterianas habían formado en sus instituciones a los que iban a ser los maestros; hasta entonces, prácticamente no existía esta profesión, "de tal manera que las personas que medianamente sabían leer, escribir y contar se podrían emplear como preceptores. También era común que las personas que no podían ganarse la vida de otra manera abrieran su propia escuela" (Galván, 2002, p. 147), ahora le tocaba el turno al gobierno de Díaz la responsabilidad de fundar las escuelas normales y de artes y oficios, cuyo requisito para integrarse a ellas era sólo concluir la instrucción primaria, la cual abarcaba los cuatro primeros grados.

En las escuelas normales se formaban hombres y mujeres, pero éstas últimas tuvieron mayor participación porque se consideró que presentaban "ciertos rasgos de carácter como el amor, la bondad y la paciencia, la mujer estaba más preparada que el hombre para enseñar a los niños" (Bazant, 2002, p. 136). Esto se vio reflejado en las estadísticas porque en 1878 el " $58 \%$ de los maestros eran hombres y $25 \%$ mujeres, pero para 1907 sólo el $23 \%$ eran hombres" (Bazant, 2002, p. 136). Los maestros percibían bajos salarios, de acuerdo con Galván (2002, p. 148) no tenían dónde vivir y podían quedarse en los establecimientos escolares, no obstante, las maestras se conformaban con salarios aún más bajos. 
Por eso, principalmente, los maestros varones emigraban de la profesión, por consiguiente "buscaban carreras más lucrativas y que por ello abandonaban el magisterio [porque] el hombre tenía abiertos muchos destinos" (Galván, 2002, p. 157). Como consecuencia, presentaban su renuncia a la autoridad correspondiente y solicitaban apoyo para estudiar alguna otra carrera que les redituara un mejor salario y prestigio social.

Los maestros atendían las escuelas de primera, en las cuales se atendían sólo a los niños, las de segunda, atendían a las niñas y las de tercera clase o mixtas se atendían a niños y niñas en la misma escuela, los niños asistían por la mañana y las niñas por la tarde, con la finalidad de no estar juntos; sin embargo, la atención de las niñas tenía que ser atendida por las maestras. En el caso de que fueran maestros y estuvieran casados, la esposa podía asistirlos en clases y se le daba un pago extra. "No obstante, hombres y mujeres normalistas, guiados por una gran vocación, ejercieron el magisterio con una 'santa misión', pues muchos de ellos tenían que caminar hasta 4 horas para dar sus clases. Obviamente la mayoría no eran titulados" (Bazant, 2002 , p. 136). Este tipo de actitudes que mantuvieron los maestros de la época porfiriana en relación con su función pudo dar como consecuencia la creación de una apología de la práctica docente. De acuerdo con Carrizales (1986), al maestro se le han construido mitos, ensalzando su función, la cual la viste de ilusiones y utopías, adornada de virtudes no correspondidas.

De esta forma, al maestro se le autorizaba a ejercer el magisterio con la obtención del título o con un examen de reconocimiento avalado por las autoridades locales o por personas respetables de la comunidad; sin embargo, podía ser despedido si no había enseñado bien a los niños o si no contaba con la simpatía del jefe político o de los dirigentes de las Juntas de Instrucción:

De tal forma que los maestros preparaban con ahínco a los niños, que se sujetaban a esas pruebas que por su solemnidad parecería que se trataba de exámenes doctorales. Llevados a cabo frente a un inspector, este determinaba si los niños habían aprendido lo requerido por la ley; si el maestro podía continuar con su trabajo de acuerdo con el amor y respeto demostrado por los niños hacia él y a sus enseñanzas. (Bazant, 2002, p. 136)

El maestro urbano, por lo general, era titulado, percibía un mejor sueldo, tenía prioridad para ocupar los mejores lugares y podía trasladarse a la capital,

1 En 1884 aún se presentaban exámenes semestrales para evaluación de los alumnos, donde se podía cuestionar el trabajo no sólo de los alumnos, sino del maestro, esto consta en un acta de examen del municipio de Papalotla, Estado de México (AHMT). 
era de los preferidos para ocupar las plazas y contaba con una vivienda, ya que la escuela donde laboraba tenía mejores recursos. Además, al no tener agrupaciones gremiales que pudieran luchar por sus derechos, se relacionaba con el presidente por medio de cartas por asuntos de licencias, empleo en la capital, jubilaciones, petición de ropa y de libros (Galván, 2002).

Al iniciar los procesos de federalización en 1921, con la creación de la SEP por José Vasconcelos, se enfatizó el problema de analfabetismo en el país; para combatirlo se requería fundar escuelas normales rurales, las cuales propiciarían una "capacitación rápida e incluso itinerante de maestros" (Civera, 2013, p. 34). Así, las primeras se establecieron en Michoacán, Puebla, Durango, Sonora e Hidalgo, para ingresar se solicitaba terminar sexto grado (correspondía a la Instrucción Primaria Superior) y llevar sus mesas-banco; los locales eran prestados o rentados, no existía un plan de estudios homogéneo, por lo tanto, fueron elaborados por los directores, sin mucho apoyo de los gobiernos locales, estatales y federales, esto tuvo como consecuencia el cierre de las escuelas normales y, en ocasiones, disputas por el control de ellas.

La política educativa giraba alrededor de la alfabetización, se pensaba en el propósito de la escuela, el cual era "cambiar la mentalidad de los campesinos y de los indios, ya que la ignorancia, la superstición, la pereza, el abuso del alcohol y la utilización técnicas y herramientas anacrónicas para trabajar la tierra impedían el progreso del país" (Civera, 2013, p. 41). Sin embargo, la población mostraba resistencia a asistir a las escuelas, porque era prioritario atender otras necesidades de alimentación y de repartición de tierras. Antes, estas problemáticas requerían de un maestro con una vocación de servicio y con espíritu de cooperación.

Los maestros rurales, quienes se encontraban lejos de las ciudades y de la supervisión de las autoridades, eran más independientes, incluso, si en la localidad no había maestro pagado por la autoridad local, los habitantes podían contratar a un maestro y pagarle, los aspirantes podían ser los religiosos, los boticarios y los profesionistas, quienes eran las personas más instruidas en los pueblos. De esta forma, gozaron de prestigio y su labor trascendía el aula de clase al involucrarse con las problemáticas de la localidad donde prestaban sus servicios: "Muchas veces eran los maestros rurales quienes firmaban documentos pidiendo agua o tierras para los lugareños; también eran ellos quienes leían la prensa si es que llegaba" (Galván, 2002, p. 162), eso trajo como consecuencia su adherencia a la comunidad, aceptación, participación y reconocimiento, por lo que su figura era la de líderes sociales. 
La escuela se convirtió en el instrumento de las autoridades para formar al ciudadano, la función de educar a los maestros normalistas fue difundir una enseñanza basada en los nuevos planteamientos, desde el siglo XIX hasta el XX. Con la federalización de la enseñanza, los maestros protagonizaron el nuevo ejército intelectual para transmitir la política educativa y los planteamientos del gobierno; se colocaron como piezas importantes para la sociedad para modelar la conciencia colectiva de un país. Entonces, ¿por qué se minimizó su profesión? Para cambiar su percepción se requirió reflexionar sobre ella, "pensar lo impensable, eliminar su certeza y seguridad y [...] transformar la estructura interpretativa de su experiencia" (Carrizales, 1986, p. 32), se invitó a los maestros a transformar lo visible y también lo oculto y a pensar en lo que no se puede pensar.

Otra de las ocupaciones de los maestros fue la de abordar las relaciones de género porque conformaba una característica promovida por la SEP al fomentar las escuelas mixtas "en la organización de la participación de niños (as), maestros (as) en la nueva escuela rural representó un verdadero obstáculo al avance de los planteles de la federación" (Alfonseca, 2016, p. 230); no obstante, generó controversia dentro y fuera de la escuela.

La formación y práctica docente del maestro de fin de siglo y el siglo XXI De 1940 a 1960 se inició un proceso de industrialización, el cual originó un crecimiento poblacional y, por consecuencia, la migración y expansión educativa en zonas como Naucalpan, Ecatepec y Nezahualcóyotl, lugares cercanos a la ciudad de México; por lo tanto, se requería de una formación técnica en las escuelas para que los alumnos pudieran incorporarse al ámbito laboral. Dado este crecimiento, aumentó la demanda de servicios y, por consiguiente, hubo una mayor cobertura educativa.

En esta época se concebía a la educación como un elemento esencial para mejorar la condición social y no sólo para superar el problema del analfabetismo en el país, porque a alguien analfabeta "se le miraba como ignorante, inculto, miserable, reacio a la ilustración, incapaz, e incluso como una persona enferma [...] se le miraba como un problema, como un lastre pernicioso" (Escalante, 2015, p. 216); por lo tanto, esta concepción estuvo cargada de prejuicios y estigmatizaciones. Con el paso del tiempo, el tipo de familias comenzó a cambiar porque de ser grandes ahora se pretendía fomentar la familia nuclear, surgió, por ejemplo, el slogan "la familia pequeña vive mejor" con la intención de disminuir el número de habitantes. 
En la década de los setenta, la ley de educación de 1973 consideró a la educación "como un proceso permanente con dos objetivos sociales: transformar la economía y la sociedad para modernizar las mentalidades y promover un orden justo que distribuyera las oportunidades equitativamente" (Vázquez, 2012, p. 221), para llevar al país al progreso. Con este propósito se impulsó la reforma de los programas de estudio y se editaron los libros de texto de educación primaria para responder a un cambio constante del conocimiento, con una actitud científica y acabar con las prácticas de enseñanza rutinarias. A los alumnos se les repartió libros de texto gratuito, los cuales estuvieron vigentes hasta 1992. Mientras, a la población rural e indígena se le dotó de libros de texto en lenguas indígenas; no obstante, el proyecto educativo no logró consolidarse por la falta de recursos. En 1978, se promovió la mejora de:

[La] enseñanza normal y la capacitación del magisterio en servicio y evaluación del rendimiento escolar [un año después] se promovieron acuerdos entre las normales federales y estatales para regular la admisión de estudiantes, reducir la matrícula y formar el bachillerato pedagógico. (Vázquez, 2012, pp. 224-225)

La finalidad de lo anterior fue mejorar la calidad educativa y ofrecer el nivel de licenciatura, con una duración de cuatro años. A los estudiantes cuando egresaban de las escuelas normales se les daba una plaza base, aunque muchas veces al incorporarse al trabajo educativo la plaza dada no coincidía con lo aprendido en la Normal y sólo se aseguraba su estancia en el sistema educativo y la percepción de un salario. Una de las sugerencias metodológicas para la enseñanza por parte de la SEP fue el aprovechamiento de los medios de comunicación para la difusión de programas educativos, libros de consulta, historietas, fotonovelas, serie de episodios mexicanos, eventos académicos y de arte.

A pesar del aumento en el rubro educativo en la calidad de la enseñanza, la preocupación no fue ahora por la alfabetización sino por la reprobación y la deserción escolar, de esta manera se dotó a las escuelas de material didáctico como el "diccionario enciclopédico, juegos geométricos para los maestros, mapas de la República de cada Estado; así como, los continentes, láminas históricas y del cuerpo humano, un aparato de mimeógrafo y una tabla de valores alimenticios" (Vázquez, 2012, p. 224). Con ello, los maestros podían hacer las adecuaciones pedagógicas para un mejor desarrollo de la enseñanza, 
por lo que exigió su reentrenamiento.

Los avances educativos retrocedieron por los cambios constantes de los secretarios de la SEP, pero también por la disminución del financiamiento de la federación, principalmente en el periodo de 1970-1989, y el anuncio inminente de un nuevo modelo económico como lo era el neoliberalismo y el fenómeno de globalización.

Se promovió el ideal de la modernización educativa el cual "repetía los tradicionales objetivos de mejorar la calidad de la enseñanza, aumentar la escolaridad, descentralizar por completo el sistema e intentar que la sociedad participara en la tarea" (Vázquez, 2012, p. 231). Aparentemente se reconfigura la educación: se fomentó una historia patria sin mitos, y aumentaron los días de clase, pero como decía Carrizales (1986), se cambió todo para quedar igual, así pudieron generar nuevos términos y adaptarlos a los tiempos actuales, pero en esencia no había transformación. En cuanto a los maestros, no tuvieron una capacitación que modificara su enseñanza, además los estímulos salariales que recibieron quedaron en manos de los sindicatos.

Vázquez (1986) menciona que a partir del año 2000 se pretendía que las escuelas de instrucción primaria se adhirieran al programa de mejora llamado "escuelas de calidad", contaran con una enseñanza del inglés, se dotaran de tablets a las escuelas públicas y se facilitara el uso de la enciclomedia para quinto y sexto de primaria, aunque estas no llegaron a todas las escuelas del país. Los maestros no estaban capacitados para esta enseñanza y existía un desconocimiento del manejo de los nuevos recursos tecnológicos; además, los padres de familia prefirieron vender los medios tecnológicos y seguir aprendiendo con los recursos didácticos de uso fijo con los que contaba la escuela: pizarrón y gis, aunque esto también cambió porque se implementó un pizarrón blanco y un marcador, pero en esencia la práctica docente seguía siendo similar a la del pasado.

En las primeras dos décadas del siglo XXI ha existido una serie de grandes cambios educativos, entre ellos: 1) las reformas educativas realizadas en el país, sus resultados para responder a las expectativas nacionales e internacionales establecidas desde la Organización para la Cooperación y el Desarrollo Económico (OCDE); 2) la reasignación del nombre y del rol de maestro a docente y las reformas administrativas impuestas a los maestros transgrediendo su seguridad laboral; 3) la falta de seguridad en la que el 
docente se vio envuelto, a pesar de que su formación no sólo se compone de la inicial en las escuelas normales o universitarias, sino que ahora hay mayor oferta para estudiar maestrías y doctorados en escuelas oficiales y particulares, con el afán de tener una preparación permanente, la cual se "concentra en parte de la necesidad de actualizarse en cuanto a las novedades últimas de la información profesional pero también, en una parte igual o mayor aún [...] de que el yacimiento de la personalidad nunca se agota" (Bauman, 2007, p. 41); 4) el desprestigio social en el que los docentes, se han visto envueltos, ya que los medios de comunicación y las organizaciones no gubernamentales como "Mexicanos Primero" han devaluado su imagen, han sometido al docente al escrutinio social y al cuestionamiento de su práctica por parte de los educandos, de los padres de familia y la comunidad en general.

\section{Discusión y conclusiones}

Desde el pasado la figura del maestro ha impactado en quien enseña, y en cada época histórica se revelan rasgos característicos de su función, lo mismo que del alumno y de las autoridades federales, estatales y locales.

El maestro ha recibido diferentes acepciones, durante el siglo XIX se le denominó preceptor, en el siglo XX maestro o profesor y a finales del siglo XX y las primeras décadas del siglo XXI se ha denominado docente; la temporalidad ha influido en este cambio de nombre, pero también la formación. Los preceptores sabían poco de gramática, lectura, aritmética y religión, algunos apenas habían cursado el tercero o cuarto de primaria, podían ser los párrocos, las viudas, los exalumnos, pero todos ellos con escasa o nula preparación, en ocasiones bastaba con sólo saber un oficio. Asimismo, la práctica realizada tuvo como base la trasmisión de conocimientos y disciplina, aunque posteriormente hubo una preocupación por parte de las autoridades federales de crear escuelas normales para preparar a los maestros.

En el siglo $\mathrm{XX}$, con el proceso de la federalización del magisterio hubo una campaña para alfabetizar a la población, por ello se requería de nuevas formas de capacitación; además de las escuelas normales también se erigieron las Misiones Culturales, en las que un preceptor experto brindaba acompañamiento a uno novato para guiar su desempeño, enseñanza, valores y actuar, así también fomentaba su compromiso social. De este modo, dejó de ser preceptor y se convirtió en maestro y agente de transformación. Sin embargo, su práctica exigía que los alumnos adquirieran conocimientos, 
de hecho, había un ejercicio heredado por el que los estudiantes debían de presentar exámenes en todos los ramos educativos, como si se tratara de una evaluación de grado y se aplicaba anual o semestralmente como se hizo en el Estado de México.

En la transición del siglo XX al XXI al maestro se le denominó docente. Cuando llegaron a México los procesos de modernización educativa, en los que a pesar de tener una formación normalista y universitaria a nivel profesional, se convirtió en facilitador del conocimiento, de valores y actitudes para que los alumnos aprendieran de una manera más significativa. Por lo tanto, en este último momento histórico se les exige a los maestros un título para asignarles una plaza, pero aunque algunos tienen mayor preparación, las condiciones de su práctica no han cambiado mucho.

Los maestros a través del tiempo se han convertido en agentes de vanguardia del Estado, son reproductores de una ideología en su esfuerzo por penetrar en el espacio del capital privado, y desempeñar un papel de intermediario entre los empresarios y la generación de mano de obra. Es posible que lo haya hecho de manera inconsciente estableciendo normas, ejerciendo su autoridad, cambiando prácticas, haciendo más dóciles a los alumnos y capacitando a futuros ciudadanos para el trabajo.

Actualmente, el maestro sigue desempeñándose como una persona que reproduce el sistema, fortalece la obediencia en la escuela y genera empleados que en tiempos próximos se incorporarán al mercado laboral; así, en la relación educación-empleo, puede llevarlos a generar mano de obra calificada especializada, y a formar una ideología de clase pobre.

Dado lo anterior, se requiere establecer nuevas interacciones y símbolos que nos lleven a entender las viejas y actuales realidades educativas, para comprender e interpretar el comportamiento humano, en lugar de considerarlo un marco de expresión, porque el profesional como ser humano trabaja con lo que puede y no con lo deseable. A partir de ahí se construirán nuevas formas de ver el mundo y, con ello, al maestro, aunque en algunos momentos todo es incierto. Sin embargo, como lo menciona Goffman (1997) el actor educativo, aunque pierda el control de su ejercicio, tiene la obligación de recuperarlo y continuar en un diferente escenario educativo.

La sociedad actual requiere a un maestro que tome conciencia y asuma una práctica pedagógica, en la cual reflexione sobre su función, pueda generar 
cambios, se desempeñe como agente de transformación, sea capaz de impactar en sus alumnos y en la comunidad, construya sus propias utopías y asuma su compromiso con él y con los demás. Como menciona Ruth Milena (2015): el maestro construye su práctica pedagógica con su experiencia, con su conducta y con sus sentimientos, con su saber pedagógico, lo cual hace él mismo en compañía de los otros.

Por último, se requiere de una práctica pedagógica, que de acuerdo con De Lella le permita construir y reconstruirse como maestro desde su práctica en el aula, a nivel institucional, comunitario y social, con la capacidad de debatir las rutinas y estereotipos, de reflexionar sobre su praxis (teoría y prácticas), sus saberes experienciales, pedagógicos e identitarios para moverse al cambio, construir una mirada emancipadora y ser un docente intelectual. 


\section{Referencias}

AHMT. (1871-1898). Archivo Histórico Municipal de Texcoco. Expedientes 38.

Alfonseca Giner de los Ríos, J. B. (2016). La apropiación de la enseñanza por la acción en las escuelas rurales federales de Texcoco y Chalco, 1922-1940. Revista Mexicana de Investigación Educativa, 21(68), 221248. https://www.redalyc.org/articulo.oa?id=14043472010.

Bauman, Z. (2007). Los retos de la educación en la modernidad líquida. Gedisa.

Bazant, M. (2002). Unidad y democracia educativa: Meta porfiriana. En M. Bazant, Ideas, valores y tradiciones. Ensayos sobre historia de la educación en México. 129-145. El Colegio Mexiquense, A.C.

Bermúdez, M. (2002). Vueltas y revueltas. En M. Bazant, Ideas, valores y tradiciones. 111-128. El Colegio Mexiquense, A.C.

Bourdieu, P. (1997). Razones prácticas. Sobre la teoría de la acción. Anagrama.

Carrizales Retamoza, C. (1986). La experiencia docente. Línea.

Civera Cerecedo, A. (2013). La escuela como opción de vida. Fondo Editorial Estado de México.

Escalante Fernández, C. (2015). Miradas recientes a la Historia de México. El Colegio Mexiquense.

Fandiño Parra, Y., Bermúdez Jiménez, J. (2015). Práctica pedagógica subjetivar, problematizar y tansformar el quehacer docente. En R. M. Paéz Martínez, Práctica y experiencia: claves del saber pedagógico docente. 29-53. Ediciones Unisalle. http://biblioteca.clacso.edu.ar/ Colombia/fce-unisalle/20170117095042/Practicaexp.pdf.

Galván, L. E. (2002). Porfirio Díaz y el magisterio nacional. En M. Bazant, Ideas, valores y tradiciones. Ensayos sobre historia de la educación en México. 145-165. El Colegio Mexiquense, A.C. 
Goffman, E. (1997). La presentcaión de la persona en la vida cotidiana. Amorrortu editores.

Gonzalbo Aizpuru, P. (2009). Introducción a la historia de la vida cotidiana. El Colegio de México.

Páez Martínez, R. M. (2015). Práctica y experiencia: claves del saber pedagógico docente. Ediciones Unisalle. http://biblioteca.clacso.edu. ar/Colombia/fce-unisalle/20170117095042/Practicaexp.pdf.

Tardif, M. (2014). Los saberes del docente y su desarrollo profesional. Narcea, S.A. de ediciones Madrid.

Vaughan, M. K. (2000). La política cultural en la revolución. SEP.

Vázquez, J. Z. (2012). Renovación y crisis. En D. Tanck de Estrada, La educación en México. 217-247. El Colegio de México, A.C. 